\title{
Do increased availability and reduced cost of early childhood care and education narrow social inequality gaps in utilization? Evidence from Norway
}

Erin Sibley ${ }^{1 *}$, Eric Dearing ${ }^{1,2}$, Claudio O Toppelberg ${ }^{3,4}$, Arnstein Mykletun $^{5,6}$ and Henrik Daae Zachrisson ${ }^{2,5}$

* Correspondence:

erin.sibley@bc.edu

'Lynch School of Education, Boston College, Campion Hall 305D, 140

Commonwealth Ave., Chestnut Hill 02467 MA, USA

Full list of author information is available at the end of the article

\section{Abstract}

Prior theoretical models and empirical research suggest that specific parent, child, and family factors are related to the utilization of early childhood education and care (ECEC). The political context of Norway provides a unique opportunity to test whether increased availability and affordability of care over time due to policy change reduces the gap between high- and low-socioeconomic status (SES) families in utilizing center-based care compared to other care arrangements. Progressive Norwegian child care policies were also expected to reduce the effect of child and family characteristics that might make a family less likely to enroll their child in center-based care. Using a large sample from the Norwegian Mother and Child Cohort Study (MoBa, $n=60,270$ ), this research examined selection factors predicting enrollment in center-based ECEC at age 18 months across cohorts from 2002 to 2006. While families with higher parental education and income-to-needs ratios were more likely to enroll their children in center-based care, the progressive universal child care policy did succeed in reducing the utilization gap between the most and least educated families across time. The policy appeared to be protective against the effect of most other factors predictive of ECEC use, but the high number of children was still associated with underutilization.

Keywords: Child care; Parental education; Family income

\section{Background}

Increased utilization of early childhood education and care (ECEC), especially by socially disadvantaged children, is a political goal in many developed countries, including the United States (Obama 2013) and those in the European Union (European Commission 2011). Comparing advantaged versus disadvantaged children, socioeconomic gaps have been consistently documented, with children from lower-income and less educated families attending ECEC at relatively low rates (e.g., Tang et al. 2012; Zachrisson et al. 2013b). While there is an extensive literature on predictors of ECEC utilization in the United States and Europe, some of which specifically addresses children from disadvantaged families, most previous studies provide 'snapshots' within a given ECEC policy context, but few have documented the effects of ECEC policy changes. In contrast, the present study provides a longitudinal examination of ECEC utilization following a universal care provision in Norway that 
requires all municipalities to provide publicly subsidized and quality-regulated center care for all children, beginning at 1 year of age. Our primary aim was to investigate whether this policy shift led to changes in social predictors of ECEC utilization at 1.5 years and, in particular, whether socioeconomic gaps in utilization were reduced.

\section{ECEC utilization among socially disadvantaged families}

There is growing evidence, both in the United States and in Europe, that high-quality ECEC may be beneficial for children's cognitive development, especially for children from disadvantaged family backgrounds (e.g., Camilli et al. 2010; Barnett 2011; Melhuish 2011; Dearing et al. 2009; Keys et al. 2013; Duncan and Sojourner 2013), with some documented benefits into adolescence (e.g., Apps et al. 2013) and early adulthood (Havnes and Mogstad 2011). High-quality ECEC may reduce the gap in academic readiness and achievement between children from low-income families and their more affluent peers (Geoffroy et al. 2010; Dearing et al. 2009). Among low-income children, high-quality child care is associated with better socio-emotional outcomes (Votruba-Drzal et al. 2004) and better language skills (Burchinal et al., 2000). Concerns over detrimental effects of spending a large number of hours in care have also been raised with regard to children's behavioral regulation, but recent evidence from Norway indicates no association between quantity of care and behavior problems (Zachrisson et al. 2013a; Solheim et al. 2013).

It is also evident, unfortunately, that the children who may be most likely to benefit are the least likely to attend ECEC, namely, children from low socioeconomic status (SES) families. Disparities in ECEC use between higher- and lower-SES families have been observed in very different socio-political contexts across the Organization for Economic Co-operation and Development (OECD 2006) including samples from the United States, Canada, the Netherlands, and the United Kingdom (Jenkins and Symons 2001; Tang et al. 2012; Michalopoulos and Robins 2000; Vandenbroeck et al. 2008). Universal access might eliminate SES gaps in ECEC use, as was the case in the United States when kindergarten became universal, with income no longer being a predictor of enrollment (Ertas and Shields 2012). Yet, social inequality in ECEC participation is evident even in those countries with the most comprehensive ECEC and family policies (e.g., Norway and Denmark; Adema 2012). For example, a Norwegian study found that less socioeconomically advantaged families were more likely to keep their children at home longer (Zachrisson et al. 2013b).

In the present study of selection into ECEC, we were particularly concerned with two fundamental elements of SES: family income and parent education. While researchers in the social sciences have often used composite variables to represent SES (e.g., combining family income and education), we examine their distinct contributions. From a policy perspective, this is a critical point: policies that target income and education do so in a targeted fashion - i.e., SES as a composite construct is not a policy target - and, as such, estimates of their unique contributions to ECEC selection are most directly applicable to policy questions (Duncan and Magnuson 2003). In the present study, we also focused on ECEC during infancy. While in some countries - notably the United States - policy debate is centered on preschool-aged children, several other nations, including Norway, have focused on ECEC beginning in infancy, a time of exceptional brain growth that can be influenced by early learning contexts (Fox and Rutter 2010; Shonkoff and Phillips 2000). 


\section{Beyond SES: child, family, and maternal predictors of ECEC utilization}

Although most studies of selection into ECEC have focused on family SES, other family and child characteristics may affect selection into ECEC and, as such, require attention when attempting to isolate SES effects. In the present study, we considered an extensive set of family and child factors, including factors that have proven important in prior empirical work (e.g., parent employment) and factors that have received prior theoretical attention (e.g., maternal psychological well-being). Thus, we provide a brief review of the relevant literatures on these factors.

Not surprisingly, maternal employment (especially for working poor mothers) is associated with increased likelihood of ECEC use (Magnuson et al. 2005; Zaslow et al. 1998). The number of children in the household has also been studied with evidence that families with more than one child are generally less likely to use ECEC (Geoffroy et al. 2012; Johansen et al. 1996; Sylva et al. 2007) or more likely to delay entry into ECEC (Borge et al. 2004; Singer et al. 1998). Others have found that the important family size selection factor is the number of preschool-age children (Harris et al. 2002), with more than one child in that age range decreasing the likelihood of use, possibly because cumulative costs of ECEC become increasingly prohibitive.

Child gender may also affect utilization, although findings are conflicting as to girls being more (Hiedemann et al. 2004) or less (Fuller et al. 1996b) likely to start in child care earlier than boys. Difficult infant temperament has also been suggested to increase the likelihood of parents utilizing non-maternal child care across socioeconomic strata (Galambos and Lerner 1987; Sylva et al. 2007) (although some studies fail to support this, see Melhuish et al. 1991; Volling and Belsky 1993).

In addition, ethnic and racial background has been related to the utilization of nonparental care. In the United States, when compared with white children, Latino children are more likely to be exclusively in home care, whereas black children are more likely to attend center-based care (Fuller et al. 1996b; Liang et al. 2000; Radey and Brewster 2007). In the UK, Sylva et al. (2007) found no differences among ethnic groups in ECEC utilization, whereas Vandenbroeck et al. (2008) in Belgium, as well as (Zachrisson et al. 2013b) and registry-based reports (Daugstad 2006; Sæther, 2010) in Norway found that ethnic minority families were less likely to utilize center-based care.

Maternal psychological well-being has been hypothesized as a potential selection factor too, since mothers with poor mental health may have limited internal resources to find ECEC for their children (Tang et al. 2012). Yet few studies have addressed this specifically, and a recent study did not find maternal depression to predict ECEC use in the United States (Coley et al. 2014).

\section{Early childhood education and care (ECEC) in Norway}

Norway is a rich country (GDP per capita of USD \$98,565 in 2008) with an unemployment rate of 2.6\% in 2008 (United Nations 2011), high overall levels of social justice, low levels of income inequality, and a child poverty rate of 5.5\% (Bertelsmann Stiftung 2011). Norway meets eight out of ten benchmarks in UNICEF's comparison of early child service policies in the OECD countries, whereas the United States meets three, the United Kingdom meets five, and Canada meets one (UNICEF Innocenti Research Center 2008). Norwegian parents receive substantial financial support including one full year of paid parental leave after birth, of which currently 10 weeks should be taken by the father (Norwegian Labour and 
Welfare Administration, 2014). Parents can also receive cash benefits for staying home with their children during their second year of life, although this benefit is less generous. Subsidized center care from age 1 is a children's right, but not compulsory.

Since 1975, when the Norwegian legislature introduced its first 'kindergarten act' (Ministry of Education and Research 2010) ('kindergarten' is the term commonly used in Norwegian legislation for ECEC), there has been a steady increase in slots in publicly subsidized child care centers with regulated quality measures, with an initial emphasis on preschool children (age 3 or older). With new legislation in 1995, slots for 1- to 2 -year-olds were also increased. This was further intensified by a broad political agreement in 2002 which stated that all children should have access to ECEC from age 1, if their parents wanted this. As part of this agreement, child care costs were capped in 2005 to approximately NOK 2000 (\$333 USD or $€ 240$; in 2005, the median income for an individual after tax in Norway was NOK 192000 [USD \$32,000 USD or $€ 23,100$ ]) monthly with a sliding scale for lower-income families. In Norway, child care centers are either public (run by the municipalities) or private, but public subsidies, price cap, and regulations of quality standards have been equal across centers since the 2002 agreement, regardless of owner. A growing percentage of the child population was enrolled in publicly subsidized center care from 2000 to 2010, as owners (public and private) received financial support to build more slots. Although the proportion of children under the age of 1 in center-based care remained under 5\% across time (in large part due to generous parental leave policy), the proportion of 1- to 2-year-olds in center-based care rose from under $40 \%$ in 2000 to nearly $80 \%$ in 2010 , and the proportion of 3 - to 5 -year-olds from 80 to nearly $97 \%$. Quality standards in terms of pedagogical content and education level of the unit leader are regulated by law, whereas the curriculum is directed by an educational content framework plan (Ministry of Education and Research 2006). Mandatory quality standards include teacher-child ratios of 1:10 for children younger than 3 years, 1:19 for older children, and a national curriculum (Ministry of Education 2010), with teachers being required to have a 3-year tertiary degree in early childhood education. Additionally, there are untrained assistants working under each teacher, and an adult-child ratio of 3:10 for children younger than 3 years and 3:19 for older children is recommended but not enforced by law. Standards of teacher requirements and adult-child ratios are currently not entirely met in all centers (UNICEF Innocenti Research Center 2008). As a consequence, there are high and relatively homogenous quality standards across most centers (Gulbrandsen and Sundnes 2009).

\section{The present study}

In the present study, we exploit the recent gradual expansion of universal ECEC for young children in Norway, to examine whether increasing availability and decreasing costs of ECEC resulted in increased utilization at 1.5 years of age, particularly among children in socioeconomically disadvantaged families. We were especially interested in whether the policy resulted in a narrowing of ECEC utilization gaps between socioeconomically disadvantaged and advantaged families. Although most prior research on ECEC has focused on children between 3 and 5 years of age, the opportunity to study ECEC participation at 18 months was important for a number of reasons. Brain growth in the first 3 years of life is exceptionally rapid (Shonkoff and Phillips 2000), with the growth of neural pathways partly influenced by early environments via their 
consequences for gene expression (Fox and Rutter 2010). A better understanding of social disparities in the use of high-quality ECEC may prove highly relevant for building a better understanding of social disparities in later life chances. Moreover, utilization ECEC for 1 to 2 years expanded substantively in Norway in the years 2003 to 2007, for which we have available data, while it expanded less so for older children.

We hypothesized that there would be non-linear relations such that the greatest narrowing in ECEC utilization over time would be evident when comparing more affluent and educated families with the poorest and least educated families. In short, we expected the policy impacts to be largest for the most disadvantaged families because financial and human capital can operate on access to opportunities and resources in non-linear fashions (with the greatest differences at the lowest ends of the distributions; Dearing 2014) and because we expected policy levers such as sliding fee scales to have diminishing returns among more advantaged families.

\section{Method}

\section{Participants}

Data from the population-based Norwegian Mother and Child Cohort Study (MoBa; for a complete description, see Magnus et al. 2006 and www.fhi.no/morogbarn) were used in the present study. For the present study, we include information collected by questionnaire during pregnancy at the 17th week of gestation (wave 1) and after birth by mail when the child was 6 and 18 months of age (waves 4 and 5, respectively). Time-invariant characteristics were measured during the earliest waves of data collection, and time-varying characteristics relevant to early development were measured repeatedly. MoBa data collection began in 1999, with participating families coming from 421 of Norway's 428 municipalities. As of October 2010, 90,725 mothers of 108,639 children had enrolled and completed baseline assessments, which represented $42.1 \%$ of all eligible mothers in Norway. We restricted our sample to the 2002 to 2006 birth cohorts $(n=60,270)$, with the 2002 cohort being born at the time of the broad political agreement for universal ECEC and the 2006 cohort being the last for which registry data on family income were available by the time children were 18 months of age.

Potential self-selection bias in the MoBa was examined by means of differences in prevalence estimates and association measures between MoBa participants and all women giving birth in Norway on demographics, health-related behaviors, and on a number of pregnancy- and birth-related variables (Nilsen et al. 2009). Compared to all women giving birth and their children, MoBa participants were on average older and more likely to be cohabiting, and had fewer health related risks, and their children had better neonatal health. However, the relative mean differences were small $(0.3 \%-1.2 \%)$.

\section{Measures}

\section{Grouping based on income-to-needs ratio}

For our primary analyses, we divided families into four groups - low income, lower middle income, higher middle income, and high income - based on average income across the child's first 2 years of life, using the 25th, 50th, and 75th percentiles on income-to-needs as thresholds. Household income was obtained from tax records for each participating mother and for fathers who had agreed to participate in the MoBa 
(77.6\%). In cases where the father's income was missing, this was imputed by expectation maximization algorithm, including extensive information from the tax records on the mother's income, assets, and debt dating back to 1993, as well as all available demographic information including self-reported income. We calculated a ratio of family income-toneeds to provide an index of economic well-being across family sizes: total annual income was divided by the OECD poverty line for each particular year (50\% of the median income, adjusted for family size) (OECD 2011).

\section{Grouping based on educational level}

Parent's highest education level in years across mother and father was a variable available at wave 1 . Dummy variables were created to indicate whether each child had parents with the lowest levels of education ( 0 to 12 years), an intermediate level of education (12.01 to 15.50 years), or the highest level of education (15.51 years or more of education). These cutoff points correspond to a high school, college, and post-college (graduate study) education level, respectively.

\section{Selection factor variables}

Child characteristics Gender (girl =0, boy $=1$ ), birth weight (in kilograms), preterm status ( $>37$ th gestational week $=1, \leq 37$ th gestational week $=0$ ), and APGAR scores at 1 and $5 \mathrm{~min}$ after birth were retrieved via linkage to the Medical Birth Registry. Child temperament at 6 months was measured with the seven-item 'Fussy/Difficult' subscale of the Infant Characteristics Questionnaire (Bates et al. 1979). The seven items used in our study were selected on the basis of a previously published factor analysis (Japel et al. 2000). Mothers rated their babies' usual mood and temperament on a 7-point rating scale (e.g., 'The child whimpers and cries a lot'). We calculated a scale mean (with mean substitution for missing items), in which higher scores reflected greater infant difficultness. Cronbach's alpha for the seven items was .68.

Family characteristics Information on dual language status of the home (a rough proxy for non-Norwegian ethnic background) and number of children in the family, mother's and father's statuses as employed and/or student (both coded no $=0$, yes $=1$ ) prior to child care entry were reported by the mothers at wave 1 .

Maternal well-being Indicators of maternal well-being were drawn from the questionnaire completed 6 months after the child's birth (wave 4). Psychological distress (anxiety and depression) was measured using an eight-item version of the Hopkins Symptom Checklist (SCL; Hesbacher et al. 1980). Details on the development and validation of this short version can be found elsewhere (Tambs and Moum 1993; Strand et al. 2003). Mothers reported on a 4-point rating scale whether they had experienced symptoms during the last 2 weeks (e.g., 'Feeling fearful'). We calculated a scale mean (with mean substitution for missing items), in which higher scores reflected maternal psychological distress. The scale had a Cronbach's alpha of .85. Negative life events were measured as a frequency count of a list of ten negative life events experienced over the last year (e.g., 'Have you had problems at work or where you study?'), each item endorsed with 'yes' or 'no'. Relationship satisfaction was measured with the 10-item 
Relationship Satisfaction (RS10) scale constructed for MoBa. Ten statements regarding relationship quality (e.g., 'I am satisfied with the relationship to my partner') are rated on a 6-point rating scale. The RS10 scale shows good psychometric properties (see Røsand et al. 2011). We calculated a scale mean (with mean substitution for missing items), in which higher scores reflect better relational quality, and the scale had a Cronbach's alpha of 0.91 .

ECEC arrangements At 18 months, the mothers reported the type of child care arrangement that represented the child's primary care arrangement. This included 'at home with mother or father,' 'at home with unqualified child minder,' 'unqualified child minder or family day care,' and 'center care.' We computed a dichotomous variable to indicate whether the child was in the center care (1) or in another type of child care arrangement (0). Since Norwegian policy provides child care at age 1 , we chose to examine ECEC arrangements at 18 months because with September enrollments into child care, not all children would have had a chance to enroll at the start of the child care year. Additionally, research indicates that early brain growth can be influenced by the early education context at this young age (Fox and Rutter 2010; Shonkoff and Phillips 2000).

\section{Statistical analyses}

Our analyses of selection into public ECEC in Norway were conducted primarily within logit regression models in which we estimated the odds of children attending ECEC as a function of the 17 child, parent, and family characteristics for which we provide descriptive statistics in Table 1. These variables were included in all longitudinal analyses. Prior to estimating the logit models, however, we conducted descriptive analyses of the number of children in ECEC at 18 months for each of the birth cohorts, with attention to trends for the full sample as well as within-group trends for family income and parent education.

Next, we conducted the logit analyses in two steps. First, we examined associations between the predictors and ECEC attendance, averaged across all birth cohorts. Second, we examined interactions between birth cohort and the socioeconomic indicators (family income and parent education) as well as any other selection factors that proved to be significant in main effects models. This second step allowed us to determine whether the patterns of selection based on these characteristics had changed over time in Norway, namely, whether the strength of association between socioeconomic factors and ECEC attendance had weakened in later years.

In addition, for family income and parent education, we estimated linear and non-linear relations for both main effects and interactions. In the case of family income, we used two approaches to detecting non-linearity: a semilog model in which ECEC use was regressed on the log of income and a quartile model in which ECEC use was regressed on three dummy variables indicating family income quartiles (with the wealthiest quartile excluded as the comparison group). In the case of parent education, we regressed ECEC use on two dummy variables: (1) high school graduate or less versus post-graduate education (graduate education beyond a bachelor's degree) and (2) at least some college but no post-graduate education versus post-graduate education.

To adjust for sample attrition, all of our analyses were conducted using ten imputed datasets created via chained equation multiple imputation for missing values, a method 
Table 1 Descriptive statistics

\begin{tabular}{|c|c|c|}
\hline Predictor & $\mathrm{M}(\mathrm{SD}) / \%$ & $\%$ Missing \\
\hline \multicolumn{3}{|l|}{ Child characteristics } \\
\hline Male & $49 \%$ & $0 \%$ \\
\hline Temperament & $3.02(.72)$ & $14.07 \%$ \\
\hline Preterm & $3.97 \%$ & $0.30 \%$ \\
\hline Birth weight & $3,581.29(583.06)$ & $0.30 \%$ \\
\hline Apgar 1 & $8.67(1.15)$ & $0.14 \%$ \\
\hline Apgar 5 & $9.42(.77)$ & $0.12 \%$ \\
\hline \multicolumn{3}{|l|}{ Family characteristics } \\
\hline Number of children in household & $1.84(.91)$ & $0 \%$ \\
\hline Mother was employed at Q1 & $82.70 \%$ & $4.21 \%$ \\
\hline Mother was student at Q1 & $6.59 \%$ & $4.21 \%$ \\
\hline Father was employed at Q1 & $91.46 \%$ & $5.37 \%$ \\
\hline Father was student at Q1 & $4.27 \%$ & $5.37 \%$ \\
\hline Family had dual languages & $10.1 \%$ & $5.52 \%$ \\
\hline \multicolumn{3}{|l|}{ Maternal well-being } \\
\hline Maternal depression & $1.24(.35)$ & $15.38 \%$ \\
\hline Negative life events at Q4 & $.90(1.19)$ & $13.75 \%$ \\
\hline Relationship satisfaction & $1.75(.73)$ & $17.63 \%$ \\
\hline \multicolumn{3}{|l|}{ Indicators of family disadvantage } \\
\hline Parent education in years & $15.03(2.44)$ & $4.56 \%$ \\
\hline Income-to-needs ratio Q4 & $2.17(.91)$ & $0 \%$ \\
\hline Income-to-needs ratio Q5 & $2.13(.89)$ & $0 \%$ \\
\hline Mean income-to-needs ratio & $2.15(.83)$ & $0 \%$ \\
\hline \multicolumn{3}{|l|}{ Childcare utilization (\% of children) } \\
\hline 2002 cohort & $33.14 \%$ & $22.42 \%$ \\
\hline 2003 cohort & $37.41 \%$ & $24.19 \%$ \\
\hline 2004 cohort & $42.51 \%$ & $25.52 \%$ \\
\hline 2005 cohort & $49.91 \%$ & $28.40 \%$ \\
\hline 2006 cohort & $56.98 \%$ & $31.97 \%$ \\
\hline
\end{tabular}

recommended over listwise deletion of cases with missing observations (e.g., Widaman 2006). The percentage of missing data for each of the variables is included in Table 1.

\section{Results}

In Figure 1, we display the proportion of children in ECEC at 18 months, breaking the sample down by the three most common levels of parent education, and in Figure 2, we display these proportions by income quartiles. It is important to note that the birth cohorts from 2002 to 2006 correspond to ECEC use from 2003 to 2008, the latter being a wider window because children born within a single year could start ECEC in the following year or 2 years later, depending on their month of birth. Prior to holding other selection factors constant, there appeared to be narrowing gaps in ECEC use associated with both family income and parent education. For parent education, the pattern of change in ECEC usage appeared consistent with our expectation of non-linear effects such that the children with least educated parents would demonstrate the largest 


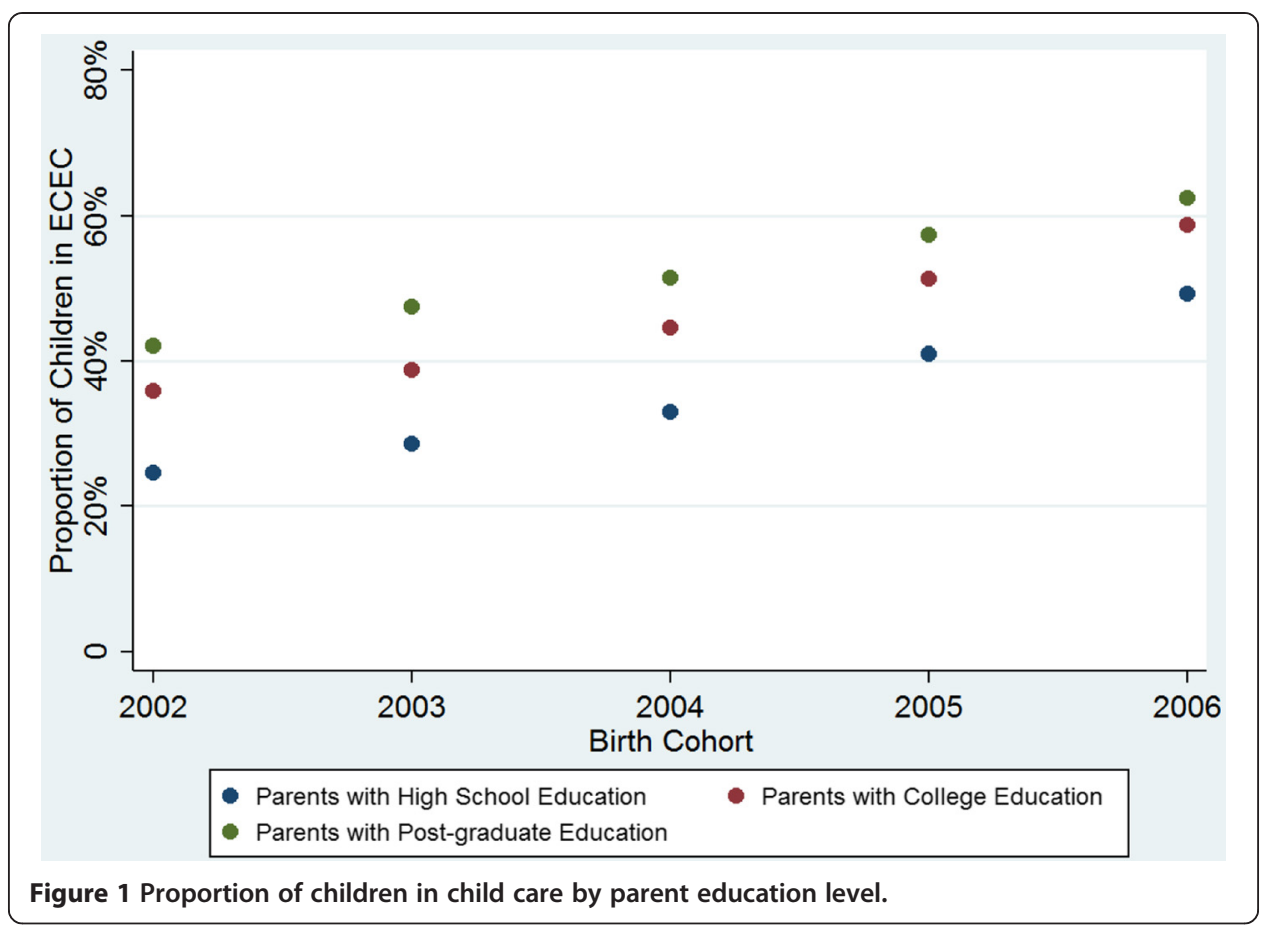

increases in use across cohorts. For family income, both of the lower two quartiles demonstrated more rapid (and fairly similar) rates of increase in ECEC use across cohorts compared with the upper two quartiles. In this latter case, it is worth noting that the unconditional pattern is somewhat different than our expectation that the poorest families (the bottom quartile) would demonstrate the largest increases, even

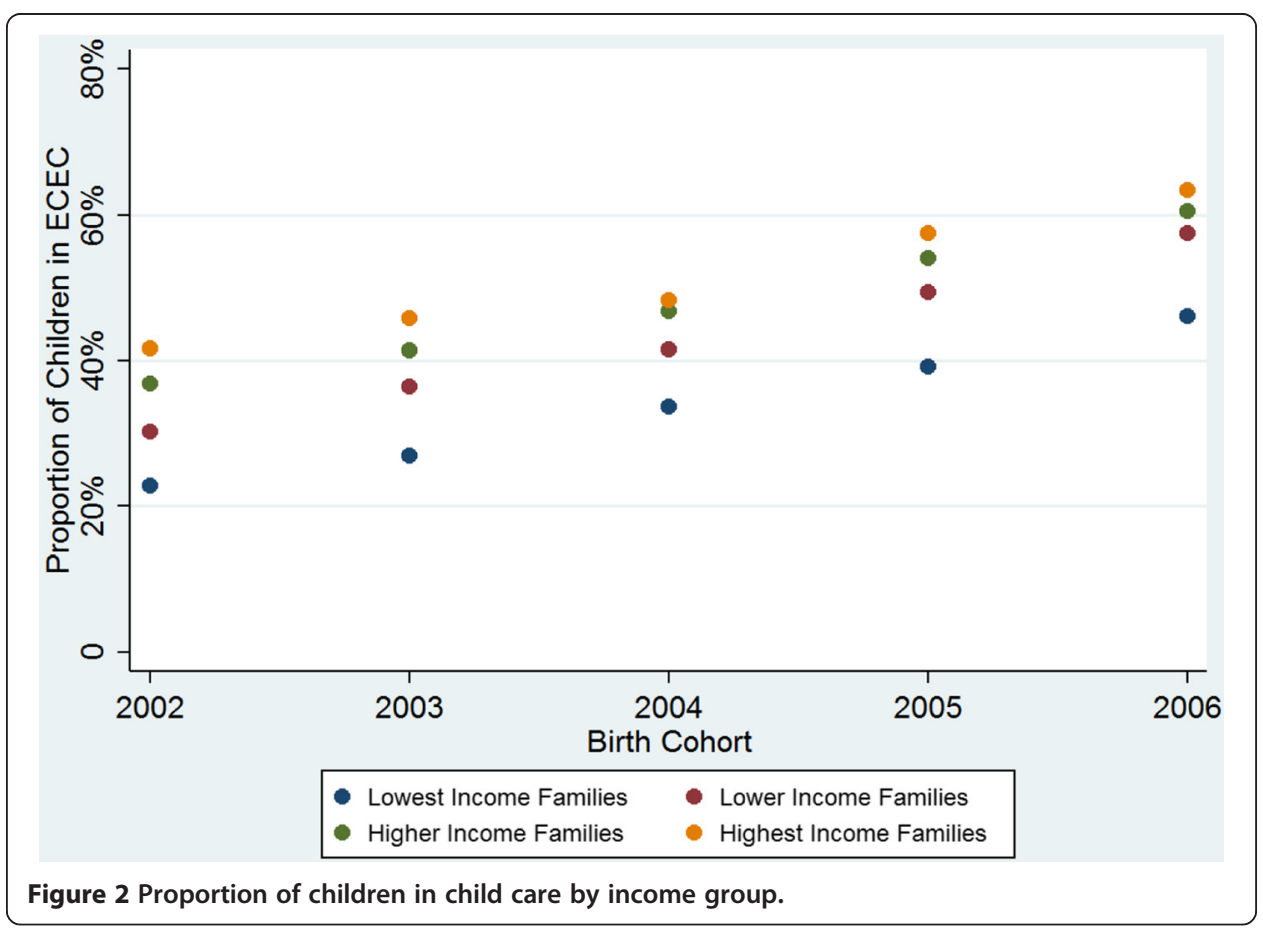


when compared to lower-income families with somewhat more financial resources (the second lowest quartile).

\section{Selection into ECEC: main effects within and across cohorts}

To follow up on these descriptive patterns, we estimated multivariate models estimating the likelihood of ECEC use as a function of the child, parent, and family characteristics. These multivariate models - estimated for all birth cohorts (holding year of birth constant) - allowed us to assess the unique contributions of each potential selection factor, averaged across birth cohorts. For most covariates, the results are displayed in Table 2. We display the results for family income-to-needs ratio and parent education in Table 3 to highlight their linear and non-linear results.

As expected and consistent with previous work, maternal employment, maternal schooling, and the number of children in the home each uniquely predicted children's likelihood of attending ECEC at 18 months. Children with mothers who were employed or who were in school, or with few or no siblings, were more likely to attend ECEC. The odds of attending ECEC for children with employed mothers were, on average across cohorts, 1.75 times greater than the odds for children with unemployed mothers. The odds for children with mothers in school were, on average, 1.72 times greater than the odds for children whose mothers were not students. For the number of siblings,

Table 2 Predictors of ECEC use: odds ratios and $95 \%$ confidence intervals

\begin{tabular}{|c|c|c|}
\hline \multirow{4}{*}{ Predictor } & \multicolumn{2}{|c|}{2002 to 2006 cohorts } \\
\hline & \multicolumn{2}{|l|}{ Average } \\
\hline & \multicolumn{2}{|c|}{ Associations } \\
\hline & OR & $95 \% \mathrm{Cl}$ \\
\hline Cohort year & $1.27^{* * *}$ & 1.23 to 1.31 \\
\hline \multicolumn{3}{|l|}{ Child characteristics } \\
\hline Male & 1.03 & .95 to 1.11 \\
\hline Temperament & 1.01 & .94 to 1.10 \\
\hline Birth weight & 1.00 & 1.00 to 1.00 \\
\hline Preterm & .80 & .46 to 1.39 \\
\hline Apgar $1 \mathrm{~min}$ & 1.01 & .94 to 1.09 \\
\hline Apgar 5 min & 1.01 & .92 to 1.10 \\
\hline \multicolumn{3}{|l|}{ Family characteristics } \\
\hline Number of children & $.92^{* *}$ & .86 to .97 \\
\hline Mother employed & $1.75^{* * *}$ & 1.40 to 2.18 \\
\hline Mother student & $1.72^{*}$ & 1.07 to 2.75 \\
\hline Father employed & 1.15 & .60 to 2.21 \\
\hline Father student & 1.18 & .69 to 2.01 \\
\hline Dual language & .97 & .77 to 1.23 \\
\hline \multicolumn{3}{|l|}{ Maternal well-being } \\
\hline Depressive symptoms & .98 & .76 to 1.28 \\
\hline Negative life events & 1.01 & .96 to 1.07 \\
\hline Relationship satisfaction & 1.00 & .92 to 1.09 \\
\hline
\end{tabular}

In all of the models displayed, parent education and family income-to-needs ratio were included as covariates. Results for these two predictors are displayed in Tables 3, 4, and 5 . ${ }^{*} p<.05 ;{ }^{* *} p<.01 ;{ }^{* * *} p<.001$. 
Table 3 Socioeconomic predictors of ECEC use: linear and non-linear specifications

\begin{tabular}{|c|c|c|}
\hline \multirow[t]{4}{*}{ Predictor } & \multirow{3}{*}{\multicolumn{2}{|c|}{$\begin{array}{l}2002 \text { to } 2006 \text { cohorts } \\
\text { Average } \\
\text { Associations }\end{array}$}} \\
\hline & & \\
\hline & & \\
\hline & OR & $95 \% \mathrm{Cl}$ \\
\hline \multicolumn{3}{|l|}{ Parent education - linear model } \\
\hline Years of education & $1.09^{* * *}$ & 1.07 to 1.11 \\
\hline \multicolumn{3}{|c|}{ Parent education - non-linear model } \\
\hline 0 to 12 years of education & $.61^{* * *}$ & .53 to .69 \\
\hline 12.5 to 15 years of education & $.82^{* * *}$ & .77 to .88 \\
\hline Family income-to-needs ratio - li & $107+$ & 09 to 116 \\
\hline Income-to-needs ratio & 1.071 & 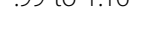 \\
\hline \multicolumn{3}{|c|}{ Family income-to-needs ratio - non-linear (semilog) model } \\
\hline Log income-to-needs ratio & $1.50^{* *}$ & 1.16 to 1.94 \\
\hline \multicolumn{3}{|c|}{ Family income-to-needs ratio - non-linear (quartile) model } \\
\hline 1st to 25 th percentile & $.68^{* * *}$ & .62 to .74 \\
\hline 26th to 50 th percentile & $.88^{* *}$ & .81 to .94 \\
\hline 51st to 75 th percentile & .96 & .89 to 1.03 \\
\hline
\end{tabular}

each additional sibling in the home was associated with a reduced odds of .92 for attending ECEC, when considering the average association across cohorts.

\section{Main effects for parent education}

Turning to the results for parent education in Table 3, each additional year of school was, on average across cohorts, associated with a 1.09-point increase in the odds of children attending ECEC, when using the linear indicator; thus, children whose parents had college degrees were, on average, estimated to be about 1.22 times more likely to attend ECEC compared with children whose parents held only a high school degree. Using the dummy variable indicators, there was some indication of non-linearity, however. Children with parents who had a high school education or less were, on average, 1.64 times (1/.61) less likely to attend ECEC at 18 months than children with parents who had a postgraduate education. Children of parents with some college, but no post-graduate education, were 1.35 times as likely to attend ECEC than parents with a high school education or less.

\section{Main effects for family income-to-needs ratio}

Using the linear levels of income-to-needs ratio, each 1-point difference (i.e., approximately $120 \%$ of a standard deviation) was associated with increased odds of attending ECEC at 18 months of 1.07, with the estimate only approaching statistical significance. However, the semilog estimate was considerably larger than the linear estimate, indicating non-linearity in the association between income-to-needs ratio and ECEC attendance when averaged across cohorts. At the lowest end of the distribution, a 1-point gain in income-to-needs ratio predicted a 1.50-point increase in odds of attending ECEC. Comparing families at higher levels of income-to-needs ratio, the differences in ECEC attendance were much smaller; for example, comparing families with income-to-needs ratios of 4 and 5, children in the families with higher income-to-needs were 1.11 times more likely 
to attend ECEC than those in families with less income-to-needs ratio. Non-linearity was also evident using the dummy variable estimators. Specifically, the disparity in ECEC use compared with the wealthiest quartile increased in a non-linear fashion at increasingly lower income-to-needs quartiles. Moving from the 51st to 75th percentile group down to the poorest, the three lower quartile groups were 1.04, 1.14, and 1.47 times less likely to attended ECEC compared with the wealthiest quartile.

Cohort differences in selection into ECEC: cohort by socioeconomic interactions

To address the primary research questions in the present study, we followed our main effect analyses with moderator analyses, examining interactions between birth cohort and family socioeconomics as predictors of selection into ECEC at 18 months.

\section{Cohort interactions for parent education}

For parent education, the results of the moderator analyses are displayed in Table 4, excluding the covariate results for brevity. The first important result evident in this table is the significant interaction term for parent education by cohort. Given an odds ratio less than one, this interaction term indicates that as birth year increased, the association between years of parent education and selection into ECEC decreased. Furthermore, because birth cohort is centered at 2002, the education main effect odds ratio corresponds to the 2002 birth cohort. In 2002, the estimated odds of ECEC use was 1.12 times higher for each additional year of education and, by 2006, this had dropped to 1.07 times. Thus, comparing children whose parents had a high school education with those who had a college education, the latter were estimated to be 1.57 times more likely to be in ECEC in 2002 and 1.35 times more likely in 2006. However, using the dummy variables for parent education, there was evidence of non-linearity in the amount of change in selection across cohorts.

The odds ratio of 1.05 for the interaction between birth cohort and 12.5 to 15 years of education indicates that the disparity in ECEC compared with children who had more highly educated parents was decreased across birth cohorts, but not as rapidly as

Table 4 Education by birth cohort interaction models: linear and non-linear specifications

\begin{tabular}{|c|c|c|}
\hline Predictor & OR & $95 \% \mathrm{Cl}$ \\
\hline \multicolumn{3}{|l|}{ Parent education interaction model 1} \\
\hline Linear education levels & $1.12^{* * *}$ & (1.09 to 1.15$)$ \\
\hline Birth cohort & $1.27^{* * *}$ & (1.23 to 1.31$)$ \\
\hline Education $\times$ cohort & $.99 * *$ & (.99 to 1.00$)$ \\
\hline \multicolumn{3}{|l|}{ Parent education interaction model 2} \\
\hline 12.5 to 15 years of education & $.73^{* * *}$ & (.64 to .82$)$ \\
\hline 0 to 12 years of education & $.49^{* * *}$ & $(.41$ to .58$)$ \\
\hline Birth cohort & $1.22^{* * *}$ & (1.18 to 1.26$)$ \\
\hline 12.5 to 15 years of education $\times$ cohort & $1.05^{* *}$ & (1.01 to 1.09$)$ \\
\hline 0 to 2 years of education $\times$ cohort & $1.08^{* * *}$ & (1.04 to 1.13$)$ \\
\hline
\end{tabular}

All covariates displayed in Table 1 and log of income-to-needs effects were controlled in these models. For interaction terms, significant odds ratios less than 1 indicate a narrowing selection gap between families with relatively high versus low levels of the covariate in question. ${ }^{* *} p<.01 ;{ }^{* * *} p<.001$. 
the disparity between the least and most educated parents was decreasing. Specifically, in 2002, the most educated parents were 1.37 times more likely to have their children in ECEC as the parents with 12.5 to 15 years of education, but by 2006, this difference had dropped to 1.12 times the likelihood. For children with the least educated parents, there were even larger decreases in the disparity (compared to children with more educated parents) across birth cohorts. In 2002, children with the least educated parents were 2.04 times less likely to attend ECEC compared with children with the most highly educated parents. By 2006, the difference in likelihood of ECEC use remained statistically significant $(p<.001)$, but had been reduced by about $25 \%$; children in the least educated homes were 1.47 times less likely to attend ECEC compared with those in the most educated homes, if born in 2006.

\section{Cohort interactions for family income-to-needs ratio}

For family income-to-needs ratio, there was much less evidence of decreasing disparity in ECEC use across birth cohorts, regardless of whether we considered linear or non-linear income-to-needs ratio (Table 5). Although the coefficients were all in the expected directions, they indicated only small changes in the level of disparity in ECEC use between poorer and wealthier families. Moreover, none of the interaction terms were precise enough to reach statistical significance.

\section{Discussion}

The primary purpose of the present study was to determine whether gaps in high-quality, center-based ECEC use between socioeconomically disadvantaged and advantaged families narrowed during a time of policy-induced increases in the availability and decreases

Table 5 Income by birth cohort interaction models: linear and non-linear specifications

\begin{tabular}{|c|c|c|}
\hline Predictor & OR & $95 \% \mathrm{Cl}$ \\
\hline \multicolumn{3}{|l|}{ Income interaction model 1} \\
\hline Linear income levels & $1.14^{* * *}$ & (1.07 to 1.22$)$ \\
\hline Birth cohort & $1.27^{* * *}$ & (1.23 to 1.31$)$ \\
\hline Income $\times$ cohort & .97 & (.94 to 1.01$)$ \\
\hline \multicolumn{3}{|l|}{ Income Interaction Model 2} \\
\hline Log of income levels & $1.79^{* * *}$ & (1.37 to 2.34$)$ \\
\hline Birth Cohort & $1.27^{* * *}$ & (1.23 to 1.31$)$ \\
\hline Log of income $\times$ cohort & .93 & (.81 to 1.06$)$ \\
\hline \multicolumn{3}{|l|}{ Income interaction model 3} \\
\hline 1st to 25 th income percentile & $.64^{* * *}$ & (.54 to .76$)$ \\
\hline 26th to 50th income percentile & $.78^{* * *}$ & $(.69$ to .89$)$ \\
\hline 51st to 75 th income percentile & .93 & (.84 to 1.04$)$ \\
\hline Birth cohort & $1.25^{* * *}$ & (1.20 to 1.30$)$ \\
\hline 1st to 25 th percentile $\times$ cohort & 1.03 & (.96 to 1.10$)$ \\
\hline 26th to 50th percentile $\times$ cohort & $1.05+$ & (1.00 to 1.11$)$ \\
\hline 51st to 75 th percentilex cohort & 1.01 & (.97 to 1.06$)$ \\
\hline
\end{tabular}

All covariates displayed in Table 1 and linear parent education effects were controlled in these models. For interaction terms, significant odds ratios less than 1 indicate a narrowing selection gap between families with relatively high versus low levels of the covariate in question. ${ }^{\dagger} p \leq .10 ;{ }^{* * *} p<.001$. 
in the costs of ECEC in Norway. In an era in which many nations are implementing or debating publicly supported ECEC, Norway provides a national context of special interest as there has been a policy-initiated steady increase in publicly subsidized spaces in ECEC centers. We exploit the gradual expansion and decreases in cost of ECEC to determine whether progress toward universal access in Norway has led to changes in the patterns of families that do and do not enroll their children in child care centers, as opposed to family or other informal care. We were particularly interested in understanding changes in the associations between ECEC use and two critical socioeconomic factors: parent education and family economic standing. The importance of examining the unique contributions of education and income for these questions was evident in the disparate findings. As expected, gaps in ECEC use between more and less educated families diminished across birth cohorts, and the greatest narrowing happened between the least and most educated. On the other hand, although families of all income levels demonstrated increased use of ECEC across birth cohorts, the gap in use between high- and low-income families remained stable and did not diminish in size for later-born cohorts.

\section{Main effects of education and income}

As others have found, parent education was a positive significant predictor of ECEC usage, on average, across the birth cohorts we analyzed. Further, consistent with studies in the United States and elsewhere, we found that wealthier and more educated families were, on average, more likely to utilize formal ECEC arrangements for their children's care (e.g., Jenkins and Symons 2001; Tang et al. 2012), and this was true despite progressive policies aimed at reducing the gap between high- and low-SES families' child care choices. For the poorest families in Norway, very small differences in income relative to family needs were, on average, associated with differential likelihoods of sending their children to ECEC; for middle class and wealthier families, however, differences in family income-to-needs ratio were much less strongly associated with ECEC use. This is in line with prior research finding that financial capital can help families to access various resources in non-linear ways, with the largest differences generally being found at the lowest ends of capital distributions (Dearing 2014). The primary purpose of the present study, however, was to move beyond average associations between these socioeconomic indicators and ECEC use to directly examine changes across time during progress toward universal access. In short, we examined whether these socioeconomic disparities were shrinking over time.

\section{Cohort interactions for education and income: closing the gap?}

Moderator analyses with birth cohort indicated that the gap in ECEC usage between families with low and high education levels significantly decreased over time when education was specified in a linear fashion. Utilizing a non-linear specification, it was evident that the gap between parents with the least and most education narrowed fastest. On the other hand, although the gap between high- and low-income families' utilization of ECEC decreased, this change was small and statistically insignificant, with no evidence of nonlinearity with regard to rates of change in ECEC use. It is worth underscore, however, that these null results are also an indication that lower- and higher-income families were increasing their use of ECEC at similarly rapid rates, with approximately $20 \%$ increases across the study period regardless of family income-to-needs levels. 
Thus, these findings suggest somewhat differential effects of the universal care policy on socioeconomic disparities in ECEC use in Norway (at least through 2008, when the youngest cohort was 18 months of age), depending on whether one is considering disparities that appear to be driven by parent education versus family income. Although the lack of narrowing in SES gaps was unexpected for family income, we offer some speculative thoughts on these results. We suspect, for example, that the narrowing for parent education may be largely driven by the increased access to ECEC and, perhaps even more so, increased awareness of the value of ECEC that has followed policy implementation. In Norway, messaging campaigns from the Norwegian Ministry of Education and Research have coincided with the universal access progress, including regular national attention to the developmental value of high-quality ECEC for children (see Ministry of Education and Research 2014, for an archive of press releases, policy briefs, public reports, and campaign messages). Consistent, therefore, with researchers who have argued that parent awareness of their ECEC choices (and their understandings of what is high-quality child care; e.g., Blau 2003) is critical to determine patterns of use, above and beyond cost, we suspect that the messaging components may be one driving force behind the increases in ECEC use being largest for the least educated families. That is, added information on the value and availability of care likely is of greatest value to families who might otherwise have less access to knowledge and information on ECEC.

The fact that increased use of ECEC was similar for relatively poorer and wealthier families despite price reductions favoring the lowest-income families was surprising to us and inconsistent with some empirically based predictions of such policies (e.g., Mason and Kuhlthau 1992). However, there is also evidence that small variations in the structures/features of price reductions can have very different effects on child care use, and some families (e.g., single-parent mothers) may be less responsive to pricing changes than others (e.g., two-parent married households; Kimmel 1998). In Norway, lowered costs may not, to this point, financially favor families at the low end of the distribution. In fact, a national report based on data from 2010 indicated that child care costs in Norway average about $5 \%$ of pre-tax income for middle and wealthier income families, but $12 \%$ of pre-tax income for low-income families (Moafi and Bjørkli 2011). In addition, Norway has since 1996 had a cash-for-care program for 1- and 2-year olds, providing a small financial compensation to parents staying home with their children until age 2 (Ministry of Children and Family Affairs 1997). This may have produced an incentive for some low-income families to keep their young children at home, but unfortunately data on the cash-for-care program was not available for inclusion in our analyses. We believe that a followup to our findings, with updated ECEC use over the last 5 to 6 years, will be critical for determining whether pricing structures are in need of change to drive up use among the poorest families.

\section{Other factors predicting ECEC utilization}

None of the child characteristics were significantly related to likelihood of enrollment in ECEC. Selected maternal and family characteristics were significantly predictive of selection into ECEC, however. Not surprisingly, for example, families with mothers who were either employed or were in school were significantly more likely to choose center-based care for their children across cohorts. The finding that employed mothers 
were more likely to choose center-based care than those who were not employed is in line with work-support theory, which posits that high-quality, subsidized ECEC may help parents effectively manage their work-school-family balance by providing a stable, affordable place to send their children while they pursue their education or career (Waldfogel 2006).

Additionally, families with fewer children were significantly more likely to use centerbased care than families with more children. In fact, a first-born child was 1.09 times as likely to attend ECEC as a second-born child. This finding is in agreement with prior work finding that families with multiple children were less likely to use ECEC (Harris et al. 2002; Johansen et al. 1996). Yet, many of these prior studies used samples from the United States, where ECEC can be exorbitantly expensive for all but the poorest children (exceptions include federal- and state-subsidized ECEC for low-income children such as Head Start, and a few states provide free universal preschool, for example, Oklahoma's universal preschool program; Gormley and Gayer 2005). For example, in 2012, the average annual cost of center-based child care for an infant in the United States ranged from a low of $\$ 4,863$ in Mississippi to a high of $\$ 16,430$ in Massachusetts (Child Care Aware of America 2013). This is a presumably unaffordable price for many families to pay for multiple children to attend ECEC. In the Norwegian context, legislation increasing the affordability of ECEC decreased financial barriers. Thus, the fact that family size remained a significant selection factor indicates that when women have multiple children, they may be more likely than for a single child to stay home to care for them for reasons beyond cost. Furthermore, it is possible that unmeasured factors correlated with family size, such as perceptions of maternal care versus center-based care, may be at play. For example, it could be that families that choose to have more children tend to have values that align more with the role of the mother staying at home to care for children.

None of the maternal well-being factors (depressive symptoms, negative life events, or relationship satisfaction) were significantly associated with children's center-based care attendance, a finding consistent with studies of United States samples (Tang et al. 2012; Yoshikawa 2001) and another Norwegian sample (see Zachrisson et al. 2013b). With regard to family characteristics, however, one null finding was of special significance: families with dual language status, a proxy for immigrant status, did not have lower odds of sending their children to ECEC, perhaps an indicator of success of the universal access policy. In the United States, immigrant parents have been found to rely more on maternal care and less on ECEC compared to non-immigrants (Tang et al. 2012), which may be in part due to cultural preferences (Fuller et al. 1996a; Magnuson et al. 2006), as well as the fact that since the passage of welfare reform in 1996, immigrants are less likely to use public benefits they are entitled to (Fix and Passel 2003), and this may include child care vouchers. Norway's progressive policy may be helping to prevent inequality in access between immigrants and non-immigrants, which may be especially important as the foreign-born population in Norway continues to rise. However, it is important to note that language spoken at home was a proxy for immigrant status and did not identify where immigrants were from their generational status, etc.

\section{Study limitations}

Despite the strengths of a large population-based sample used for these analyses, there are a few limitations that must be considered when interpreting our results. First, these 
analyses were correlational in nature. Omitted variables bias was a potential threat and we could not identify the causal effects of education or income for selection into ECEC. There may have been other cultural values, parent or child health factors, or personal beliefs that made some parents choose a specific ECEC option, if any, for their children. Second, although this is a very large sample of Norwegian families, it is important to note that only $42.1 \%$ of eligible mothers in Norway participated in MoBa at baseline, and it is unlikely that participation versus non-participation was random. Third, our comparisons focused on selection into childcare versus any other type of childcare and did not examine the possibility of combinations of child care arrangements; although this is less common in Norway than in the United States (Zachrisson et al. 2013b), it is possible that additional factors were at play when predicting selection into various other child care arrangements (such as maternal care, relative care, or home-based child care centers). Fourth, while we did not find dual language background to predict ECEC utilization, it is notable that the barriers associated with completing a comprehensive postal questionnaire in Norwegian may have been an obstacle for recruiting non-western immigrants in MoBa. This is evident by the fact that only $2.2 \%$ of dual language participants reported Urdu spoken at home, while Pakistanis (i.e., Urdu speakers) are among the largest immigrant groups in Norway with a population of about 37,000 (Ministry of Foreign Affairs 2008). The majority (84.3\%) of dual language speakers reported 'other' language than Sami (native Norwegian 1.6\%), English (9.6\%), or combinations of these $(2.3 \%)$. The national and language backgrounds of these groups were therefore largely unknown and may have mostly included participants from EU member states like Poland or Sweden, both countries with large populations in Norway. Finally, the fact that Norwegian parents can receive cash benefits for staying home with their children during their second year of life may be a confounding factor in interpreting the results.

Nonetheless, given the novelty of our examining changes in ECEC use during a time of policy change, the present study adds to the existing research, which has primarily relied on snapshots of individual cohorts of children either at a single point in time, averaged across time, or during times of relatively stable policy.

\section{Conclusion}

The present study provides a strong demonstration that when high-quality ECEC is available and affordable, the potential barriers of low parental education and low family income are partially mitigated. Indeed, with regard to parent education, we find good evidence that Norway's universal ECEC policy is reducing disparities between more and less advantaged families with regard to the utilization of formal early childhood education and care. The implications of this reduced ECEC disparity may, in the end, prove vital for promoting the well-being of socially disadvantaged children in Norway, and the nation at large. In addition to the important role of access to affordable ECEC for promoting workforce participation and maternal psychosocial well-being (Buehler and O'Brien 2011), children who attend high-quality ECEC may have better long-term outcomes that also have economic returns on society (Belfield et al. 2006). Other nations should consider Norway's example in order to reduce some of the barriers to ECEC faced by families with low parental education and income. 


\section{Competing interests}

The authors declare that they have no competing interests.

\section{Authors' contributions}

ES had primary responsibility for the guiding ideas behind the paper and for writing the manuscript as well as secondary responsibility for data analyses; ED had primary responsibility for data analyses and secondary responsibility for writing the manuscript; $\mathrm{HZ}$ had tertiary responsibility for data analysis and writing the manuscript; $\mathrm{CT}$ and $\mathrm{AM}$ contributed to the writing of the manuscript. All authors read and approved the final manuscript.

\section{Acknowledgements}

The authors acknowledge the Norwegian Mother and Child Cohort Study, which is supported by the Norwegian Ministry of Health, NIH/NIEHS (grant no. N01-ES-85433) and NIH/NINDS (grants nos.1 UO1 NS 047537-01 and UO1 NS 047537-06A1).

\section{Author details}

'Lynch School of Education, Boston College, Campion Hall 305D, 140 Commonwealth Ave., Chestnut Hill 02467 MA, USA. ${ }^{2}$ The Norwegian Center for Child Behavioral Development, 0306 Oslo, Norway. ${ }^{3}$ Harvard Medical School, Boston 02115 MA, USA. ${ }^{4}$ Judge Baker Children's Center, Boston 02120 MA, USA. ${ }^{5}$ Norwegian Institute of Public Health, Bergen 5018 Oslo, Norway. ${ }^{6}$ University of New South Wales, Sydney 2052 NSW, Australia.

Received: 9 July 2014 Accepted: 5 December 2014

Published online: 26 February 2015

\section{References}

Adema, W. (2012). Setting the scene: The mix of family policy objectives and packages across the OECD. Children and Youth Service Review, 34, 478-498. doi:10.1016/j.childyouth.2011.10.007.

Apps, P, Mendolia, S, \& Walker, I. (2013). The impact of pre-school on adolescents' outcomes: Evidence from a recent English cohort. Economics of Education Review, 37, 183-199. doi:10.1016/j.econedurev.2013.09.006.

Barnett, WS. (2011). Effectiveness of early educational intervention. Science, 333, 975-978. doi:10.1126/science.1204534.

Bates, JE, Freeland, CAB, \& Lounsbury, ML. (1979). Measurement of infant difficultness. Child Development, 50(3), 794-803. doi:10.2307/1128946.

Belfield, CR, Nores, M, Barnett, S, \& Schweinhart, L. (2006). The High/Scope Perry Preschool Program cost-benefit analysis using data from the age-40 followup. Journal of Human Resources, 41(1), 162-190.

Bertelsmann Stiftung (2011). Social justice in the OECD—How do the member states compare? Available from http://www.sgi-network.org/pdf/SGl11_Social_Justice_OECD.pdf.

Blau, DM. (2003). Child care subsidy programs. In RA Moffitt (Ed.), Means-tested transfer programs in the United States (pp. 443-516). Chicago: University of Chicago Press.

Borge, Al, Rutter, M, Côté, S, \& Tremblay, RE. (2004). Early childcare and physical aggression: differentiating social selection and social causation. Journal of Child Psychology and Psychiatry, 45(2), 367-376. doi:10.1111/j.1469-7610.2004.00227.x.

Buehler, C, \& O'Brien, M. (2011). Mothers' part-time employment: Associations with mother and family well-being. Journal of Family Psychology, 25(6), 895. doi:10.1037/a0025993.

Burchinal, MR, Roberts, JE, Riggins, R, Zeisal, SA, Neebe, E, \& Bryant, D. (2000). Relating quality of center-based care to early cognitive and language development longitudinally. Child Development, 71(2), 339-357. doi:10.1111/1467-8624.00149.

Camilli, G, Vargas, S, Ryan, S, \& Barnett, WS. (2010). Meta-analysis of the effects of early education interventions on cognitive ans social development. Teachers College Record, 112, 579-620.

Child Care Aware of America. (2013). Parents and the high cost of child care. Retrieved from http://usa.childcareaware. org/sites/default/files/cost_of_care_2013_103113_0.pdf.

Coley, RL, Votruba-Drzal, E, Collins, MA, \& Miller, P. (2014). Selection into early education and care settings: Differences by developmental period. Early Childhood Research Quarterly, 29(3), 319-332. doi: 10.1016/j.ecresq.2014.03.006.

Daugstad, G. (2006). (The scope and utilization of cash benefits among children with non-western background) Omfang av bruk av kontantstøtte blant barn med ikke- vestlig bakgrunn. Oslo, Norway: Statistics Norway. Rep. No. 2006/26.

Dearing, E, McCartney, K, \& Taylor, BA. (2009). Does Higher Quality Early Child Care Promote Low-Income Children's Math and Reading Achievement in Middle Childhood? Child Development, 80, 1329-1349. doi:10.1111/j.1467-8624.2009.01336.x.

Dearing, E. (2014). The state of research on children and families in poverty: Past, present, and future empirical avenues of promise. In K McCartney, H Yoshikawa, \& L Forcier (Eds.), Improving the Odds for America's Children. Cambridge, MA: Harvard Education Press.

Duncan, GJ, \& Magnuson, KA. (2003). Off with Hollingshead: Socioeconomic resources, parenting, and child development. In MH Bornstein \& RH Bradley (Eds.), Socioeconomic status, parenting, and child development (pp. 83-106). London: Earlbaum.

Duncan, GJ, \& Sojourner, AJ. (2013). Can intensive early childhood intervention programs eliminate income-based cognitive and achievement gaps? Journal of Human Resources, 48(4), 945-968. doi:10.1353/jhr.2013.0025.

Ertas, N, \& Shields, S. (2012). Child care subsidies and care arrangements of low-income parents. Children and Youth Services Review, 34(1), 179-185. doi:10.1016/j.childyouth.2011.09.014.

European Commission. (2011). Early Childhood Education and Care: Providing all our children with the best start for the world tomorrow. Brussels: Eurpoean Commission.

Fix, M, \& Passel, J. (2003). The scope and impact of welfare reform's immigrant provisions. Washington, D.C.: Urban Institute. 
Fox, NA, \& Rutter, M. (2010). Introduction to the special section on the effects of early experience on development. Child Development, 81(1), 23-27. doi:10.1111/j.1467-8624.2009.01379.x.

Fuller, B, Eggers-Pierola, C, Holloway, S, \& Liang, X. Rambaud, MF. (1996a). Rich culture, poor markets: Why do Latino parents forgo preschooling. The Teachers College Record, 97(3), 400-418.

Fuller, B, Holloway, SD, \& Liang, XY. (1996b). Family selection of child-care centers: The influence of household support, ethnicity, and parental practices. Child Development, 67, 3320-3337. doi:10.2307/1131781.

Galambos, NL, \& Lerner, JV. (1987). Child characteristics and the employ- ment of mothers with young children: A longitudinal study. Journal of Child Psychology and Psychiatry, 28, 87-98. doi: 10.1111/j. 1469-7610.1987.tb00654.x.

Geoffroy, MC, Cote, SM, Giguere, CE, Dionne, G, Zelazo, PD, Tremblay, RE, Boivin, M, \& Seguin, JR. (2010). Closing the gap in academic readiness and achievement: the role of early childcare. Journal of Child Psychology and Psychiatry, 51, 1359-1367. doi:10.1111/j.1469-7610.2010.02316.x.

Geoffroy, MC, Séguin, JR, Lacourse, É, Boivin, M, Tremblay, RE, \& Côté, SM. (2012). Parental characteristics associated with childcare use during the first 4 years of life: results from a representative cohort of Quebec families. Canadian Journal of Public Health, 103(1), 76-80.

Gormley, WT, \& Gayer, T. (2005). Promoting school readiness in oklahoma an evaluation of tulsa's pre-k program. Journal of Human Resources, 40(3), 533-558.

Gulbrandsen, L, \& Sundnes, A. (2009). Kvalitet og kvantitet - kvalitet i en barnehagesektor i sterk vekst [Quality and quantity- Quality in a child-care seector in rapid growth]. (Research report 2/2009). Oslo, Norway: NOVA.

Harris, KM, Raley, RK, \& Rindfuss, RR. (2002). Family Configurations and Child-Care Patterns: Familes with Two or More Preschool-Age Children. Social Science Quarterly, 83(2), 455-471. doi:10.1111/1540-6237.00094.

Havnes, T, \& Mogstad, M. (2011). No child left behind: Subsidized child care and children's long-run outcomes. American Economic Journal: Economic Policy, 3(2), 97-129. doi: 1 0. 1257 /pol 3. 2. 97.

Hesbacher, PT, Rickels, K, Morris, RJ, Newman, H, \& Rosenfeld, H. (1980). Psy- chiatric illness in family practice. Journal of Clinical Psychiatry, 41, 6-10.

Hiedemann, B, Joesch, JM, \& Rose, E. (2004). More daughters in child care? Child gender and the use of nonrelative child care arrangements. Social Science Quarterly, 85, 154-168. doi: 0.1111/j. 0038-4941.2004.08501011.x.

Japel, C, Tremblay, RE, McDuff, P, \& Boivin, M. (2000). Temperament in longitudinal study of child development in Quebec (ÉLDEQ 1998-2002). Quebec: Institut de la statistique du Quebec, 1.

Jenkins, SP, \& Symons, EJ. (2001). Child care costs and lone mothers' employment rates: UK evidence. The Manchester School, 69(2), 121-147. doi:10.1111/1467-9957.00238.

Johansen, AS, Leibowitz, A, \& Waite, L. (1996). The importance of child-care characteristics to choice of care. Journal of Marriage and the Family, 58, 759-772. doi:10.2307/353734.

Keys, TD, Farkas, G, Burchinal, MR, Duncan, GJ, Vandell, DL, Li, W, et al. (2013). Preschool Center Quality and School. Readiness: Quality Effects and Variation by Demographic and Child Characteristics. Child Dev. doi:10.1111/ cdev. 12048.

Kimmel, J. (1998). Child care costs as a barrier to employment for single and married mothers. Review of Economics and Statistics, 80(2), 287-299. doi:10.1162/003465398557384.

Liang, X, Fuller, B, \& Singer, J. (2000). Ethnic differences in child care selection: The influence of family structure, parental practices, and home language. Early Childhood Research Quarterly, 15, 357-384. doi:10.1016/50885- 2006(00)00071-5.

Magnuson, K, Lahaie, C, \& Waldfogel, J. (2006). Preschool and school readiness of children of immigrants. Social Science Quarterly, 87, 1241-1262. doi:10.1111/j.1540-6237.2006.00426.x.

Magnuson, K, Meyers, MK, Ruhm, CJ, \& Waldfogel, J. (2005). Inequality in children's school readiness and public funding. Focus, 24(1), 12-18.

Magnus, P, Irgens, LM, Haug, K, Nystad, W, Skjaerven, R, \& Stoltenberg, C. (2006). Cohort profile: The Norwegian Mother and Child Cohort Study (MoBa). Int J Epidemiol, 35, 1146-1150. doi:10.1093/ije/dyl170.

Mason, KO, \& Kuhlthau, K. (1992). The perceived impact of child care costs on women's labor supply and fertility. Demography, 29(4), 523-543. doi:10.2307/2061850.

Melhuish, EC, Moss, P, Mooney, A, \& Martin, S. (1991). How similar are day-care groups before the start of day care? Journal of applied developmental psychology, 12(3), 331-346. doi: 10.1016/0193-3973(91)90004-N.

Melhuish, EC. (2011). Education. Preschool matters. Science, 333, 299-300. doi:10.1126/science.1209459.

Michalopoulos, C, \& Robins, PK. (2000). Employment and child-care choices in Canada and the United States. The Canadian Journal of Economics, 33(2), 435-470. doi:10.1111/0008-4085.00023.

Ministry of Children, and Family Affairs. (1997). Introduction of cash-for-care for parents with young children. St.Prp. nr 53. Available from http://www.regjeringen.no/nb/dep/bld/dok/regpubl/stprp/19971998/stprp-nr-53-1997-98-html? regj_oss=18id=136909. Accessed April 28, 2014.

Ministry of Education. (2010). Barnehageloven [The Kindergarten Act]. Available from http://www.lovdata.no/all/ nl-20050617-064.html. Accessed January 29, 2015.

Ministry of Education and Research (2006). Framework plan. Available from http:/www.regjeringen.no/upload/kilde/kd/ prm/2006/0005/ddd/pdfv/282009-rammeplanen.pdf. Accessed January 12, 2012.

Ministry of Education and Research (2014). Early childhood education and policy. Available from http://www. regjeringen.no/en/dep/kd/Selected-topics/kindergarden/early-childhood-education-and-care-polic.html?id=491283. Accessed April 25, 2014.

Ministry of Foreign Affairs. (2008). Coherent for development? Immigration to Norway. NOU, 2008, 14. Available from https:/www.regjeringen.no/en/dokumenter/nou_coherent/id528066/.

Moafi, H, \& Bjørkli, ES. (2011). Barnefamiliers tilsynsordninger, høsten 2010 [Child care for families with children, fall 2010] (Vol. Rep. No. 34/2011). Oslo-Kongsvinger, Norway: Statistics Norway.

Nilsen, RM, Vollset, SE, Gjessing, HK, Skjærven, R, Melve, KK, Schreuder, P, \& Magnu, P. (2009). Self-selection and bias in a large prospective pregnancy cohort in Norway. Pediatric and perinatal epidemiology, 23(6), 597-608. doi:10.1111/j.1365-3016.2009.01062.x. 
Norwegian Labour and Welfare Administration. (2014). Paternal quota (paternal leave), maternal quota and shared period. Available from https://www.nav.no/en/Home/Benefits+and+services/Relatert+informasjon/Paternal+quota+ \%28paternity+leave\%29\%2C+maternal+quota+and+shared+period.353596.cms. Accessed January 29, 2015.

Obama, B. (2013). Remarks by the president on Early Childhood Education. Available from http://www.whitehouse.gov/ photos-and-video/video/2013/02/14/president-obama-early-childhood-education\#transcript.

OECD. (2006). Starting Strong II: Early Childhood Education and Care. Paris: OECD.

Organisation for Economic Co-operation and Development. (2011). Divided we stand: Why inequality keeps rising. Paris, France. Retrieved from http://www.oecd.org/els/soc/dividedwestandwhyinequalitykeepsrising.htm.

Radey, M, \& Brewster, KL. (2007). The influence of race/ethnicity on disadvan- taged mother's child care arrangements. Early Childhood Research Quarterly, 22, 379-393. doi:10.1016/S0885-2006(01)00098-9.

Røsand, GMB, Slinning, K, Eberhard-Gran, M, Røysamb, E, \& Tambs, K. (2011). Partner relationship satisfaction and maternal emotional distress in early pregnancy. BMC Public Health, 11(1), 161. doi: 10.1186/1471-2458-11-161.

Sæther, JP. (2010). (Children in center care - Parental background and recent devel- opments) Barn i barnehage foreldrebakgrunn og utvikling de seneste årene. Oslo, Norway: Statistics Norway. Rep. No. 11/2010.

Shonkoff, JP, \& Phillips, DA (Eds.). (2000). From neurons to neghborhoods. The science of early childhood development. Washington, D.C.: National Academy Press.

Singer, JD, Fuller, B, Keiley, MK, \& Wolf, A. (1998). Early child-care selection: Variation by geographic location, maternal characteristics, and family structure. Developmental Psychology, 34, 1129-1144. doi:10.1037/0012- 1649.34.5.1129.

Solheim, E, Wichstrøm, L, Belsky, J, \& Berg-Nielsen, TS. (2013). Do time in child care and peer group exposure predict poor socioemotional adjustment in Norway? Child Development, 84(5), 1701-1715. doi: 10.1111/cdev.12071.

Strand, BH, Dalgard, OS, Tambs, K, \& Rognerud, M. (2003). Measuring the mental health status of the Norwegian population: a comparison of the instruments SCL-25, SCL-10, SCL-5 and MHI-5 (SF-36). Nordic Journal of Psychiatry, 57(Strand, B. H., Dalgard, O. S., Tambs, K), 113-118. doi: 10.1080/08039480310000932.

Sylva, K, Stein, A, Leach, P, Barnes, J, \& Malmberg, LE. (2007). Family and child factors related to the use of non-maternal infant care: An English study. Early Childhood Research Quarterly, 22, 118-136. doi:10.1016/j.ecresq.2006.11.003.

Tambs, K, \& Moum, T. (1993). How well can a few questionnaire items indicate anxiety and depression? Acta Psychiatrica Scandinavica, 87, 364-367. doi:10.1111/j.1600-0447.1993.tb03388.x.

Tang, S, Coley, RL, \& Votruba-Drzal, E. (2012). Low-income families' selection of child care for their young children. Children and Youth Service Review, 34, 2002-2011. doi:10.1016/j.childyouth.2012.06.012.

UNICEF Innocenti Research Center. (2008). Report card 8: The child care tran- sition. Florence, Italy: UNICEF Innocenti Research Center. Available from http://www.unicef-irc.org/publications/pdf/rc8_eng.pdf.

United Nations. (2011). UN data country profile on Norway. Available from http://data.un.org/CountryProfile.aspx? crName=Norway

Vandenbroeck, M, De Visscher, S, Van Nuffel, K, \& Ferla, J. (2008). Mothers' search for infant child care: The dynamic relationship between availability and desirability in a continental European welfare state. Early Childhood Research Quarterly, 23, 245-258. doi:10.1016/j.ecresq.2007.09.002.

Volling, BL, \& Belsky, J. (1993). Parent, infant, and contextual characteristics related to maternal employment decisions in the first year of infancy. Family Relations, 42, 4-12. doi:10.2307/584914.

Votruba-Drzal, E, Coley, RL, \& Chase-Lansdale, PL. (2004). Child care and low-income children's development: Direct and moderated effects. Child Development, 75, 296-312. doi:10.1111/j.1467-8624.2004.00670.x.

Waldfogel, J. (2006). What do children need? Public Policy Research, 13(1), 26-34. doi:10.1111/j.1070-3535.2006.00417.x.

Widaman, KF. (2006). III. Missing data: What to do with or without them. Monographs of the Society for Research in Child Development, 71(3), 42-64.

Yoshikawa, H. (2001). Variation in teenage mother's experiences of childcare and other components of welfare reform. Child Development, 72, 299-317. doi:10.1111/1467-8624.00280.

Zachrisson, HD, Dearing, E, Lekhal, R, Toppelberg, CO. (2013a). Little Evidence That Time in Child Care Causes Externalizing Problems During Early Childhood in Norway. Child Dev.. doi: 10.1111/cdev.12040

Zachrisson, HD, Janson, H, \& Nærde, A. (2013b). Predicting early center care utilization in the context of universal access. Early Childhood Research Quarterly, 28(1), 74-82. doi:10.1016/j.ecresq.2012.06.004.

Zaslow, MJ, Oldham, E, Moore, KA, \& Magenheim, E. (1998). Welfare families' use of early childhood care and education programs, and implications for their children's development. Early Childhood Research Quarterly, 13(4), 535-563. doi:10.1016/S0885-2006(99)80058-1.

\section{Submit your manuscript to a SpringerOpen ${ }^{\oplus}$ journal and benefit from:}

- Convenient online submission

- Rigorous peer review

- Immediate publication on acceptance

- Open access: articles freely available online

- High visibility within the field

- Retaining the copyright to your article

Submit your next manuscript at $>$ springeropen.com 